\title{
Indicador de eficiencia recaudatoria del impuesto al valor agregado y del impuesto a la renta del Ecuador ${ }^{1}$
}

\author{
José Ramírez-Álvarez y Paul Carrillo-Maldonado
}

\section{Resumen}

El presente estudio expone una metodología para medir la eficiencia de las administraciones tributarias en la recaudación de impuestos. Esta propuesta se dirige en especial a países en desarrollo que no tienen suficiente información desagregada para medir las brechas tributarias (de inscripción, presentación, veracidad y pago) con los métodos tradicionales. Los índices propuestos se basan en la estimación de balances estructurales de las finanzas públicas, en tanto que su interpretación se plantea como el cierre conjunto de las brechas tributarias. Esta metodología se aplica para el impuesto al valor agregado (IVA) y el impuesto a la renta (IR) del Ecuador, y el resultado evidencia que el crecimiento de la recaudación se ha producido por una mayor eficiencia de su administración tributaria.

\section{Palabras clave}

Impuesto a la renta, impuesto al valor agregado, recaudación de impuestos, evasión tributaria, administración fiscal, evaluación, Ecuador

\section{Clasificación JEL}

$\mathrm{H} 21, \mathrm{H} 26, \mathrm{H} 83$

\section{Autores}

José Ramírez-Álvarez es Doctor en Economía, Profesor del Departamento de Economía Cuantitativa de la Escuela Politécnica Nacional, Ecuador. Correo electrónico: jose. ramirez@epn.edu.ec.

Paul Carrillo-Maldonado es Analista Económico del Banco Interamericano de Desarrollo, candidato a doctor en el Programa Doctoral de la Facultad Latinoamericana de Ciencias Sociales (FLACSO). Correo electrónico: paulcar@iadb.org.

\footnotetext{
1 Los autores agradecen los comentarios de Javier Díaz Cassou, Juan Luis Gómez, Alberto Barreix, Edwin Buenaño, Víctor Morales Oñate, Ana Oña, Diana Arias, Ximena Amoroso, Gonzalo Sánchez Lima, Verónica Acurio Vásconez, Liliana Cano y Thais Núñez. Las opiniones, los errores y las omisiones son de responsabilidad exclusiva de los autores y no de las instituciones.
} 


\section{Introducción}

La gestión tributaria es una función administrativa de vital importancia para el Estado, pues refuerza la suficiencia de los recursos públicos para la ejecución del gasto y la inversión, y resguarda la equidad y la redistribución en la estructura fiscal de un país. Su ejercicio está a cargo de la administración tributaria y comprende básicamente la recaudación de tributos, la fiscalización de las obligaciones tributarias y la liquidación de impuestos (Jorratt, 1996).

En esencia, la gestión tributaria abarca el manejo y seguimiento de cuatro brechas: la de inscripción, la de presentación (o declaración), la de veracidad y la de pago. La primera es la diferencia entre el número de contribuyentes inscritos y la población potencial (normalmente, la población económicamente activa ocupada). La segunda es la diferencia entre el total de declaraciones que los contribuyentes inscritos con actividad económica activa deberían realizar y el número de declaraciones presentadas. La brecha de pago es la diferencia entre el impuesto pagado dentro de los plazos establecidos y el valor declarado voluntariamente por los contribuyentes. La brecha de veracidad es la diferencia entre el valor declarado y el monto determinado por la administración tributaria mediante la fiscalización (Pecho, Sánchez y Peláez, 2012).

La disminución coordinada de estas brechas es uno de los objetivos prioritarios para definir la estrategia de la administración tributaria y medir su desempeño como entidad recaudatoria de impuestos. La literatura especializada ha reseñado distintos métodos para estimar cada una de las brechas. Pecho, Sánchez y Peláez (2012) presentan estas metodologías y exponen sus resultados para América Latina entre 2000 y 2010. No obstante, los autores muestran que su viabilidad técnica depende de la disponibilidad y la calidad de la información externa a la administración tributaria, lo que impide realizar un seguimiento integral de la gestión tributaria. Alm y Duncan (2014), además, proponen utilizar las metodologías input-output (análisis por envoltura de datos (Data Envelopment Analysis) y análisis de frontera estocástica (Stochastic Frontier Analysis)) para medir la eficiencia de la administración tributaria y de sus agencias. Sin embargo, esta iniciativa es difícil de aplicar en economías emergentes por la poca información disponible sobre el costo de los procesos administrativos, la operación de los contribuyentes por fuente externa y el presupuesto a nivel administrativo-geográfico, entre otros factores.

El presente estudio plantea una metodología para la construcción de índices de eficiencia recaudatoria con base en información macroeconómica. La metodología se fundamenta en la estimación de un balance estructural de las finanzas públicas (véase Fedelino, Ivanova y Horton, 2009), considerando solo el lado de ingresos fiscales; es decir, eliminando los efectos de las condiciones económicas y de las reformas tributarias que se hayan producido. El indicador expuesto muestra el cierre conjunto de las brechas tributarias antes mencionadas. Esta propuesta se aplica a la administración tributaria del Ecuador (Servicio de Rentas Internas (SRI)) y de manera específica al impuesto al valor agregado (IVA) y el impuesto a la renta (IR). El caso ecuatoriano es particularmente interesante por tratarse de un país en desarrollo que en los últimos años ha logrado incrementos sustanciales en la recaudación, en claro contraste con otros períodos históricos (Almeida y otros, 2012).

Los resultados del trabajo indican que la eficiencia del SRI ha aumentado desde 2006. Asimismo, reflejan una recuperación de la eficiencia recaudatoria del IVA desde 2007 y variaciones importantes entre 2006 y 2010 en la eficiencia recaudatoria del IR. Por último, los resultados sugieren que el comportamiento del SRI es adaptativo ante una posible disminución de la recaudación por fenómenos externos a su gestión.

Este artículo se encuentra estructurado de la siguiente manera: en la segunda sección se presenta la teoría económica relacionada con los determinantes de la recaudación tributaria; la tercera sección describe la metodología utilizada para la construcción de los indicadores de eficiencia; la cuarta sección ofrece algunos antecedentes de la recaudación tributaria en el Ecuador; la quinta sección expone los resultados obtenidos para el caso del Ecuador y, finalmente, en la sexta sección se exponen las conclusiones. 


\section{Eficiencia y recaudación tributaria: lineamientos teóricos}

Según Jorratt (1996), existen dos fuentes principales para incrementar la recaudación tributaria: establecer nuevos tributos o aumentar la eficiencia con la que se recaudan los actuales. En un contexto tributario, la eficiencia comprende el cierre parcial o conjunto de las brechas tributarias a través de acciones y estrategias de control que acrecientan la percepción de riesgo de los contribuyentes y mejoran su comportamiento. Además, la Dirección General Impositiva del Uruguay (DGl, 2006) y Ricciardi (2007) mencionan que, para medir la eficiencia de la administración tributaria, es necesario distinguir tres factores que influyen en la recaudación de impuestos: la actividad económica, la política tributaria y el cumplimiento de las obligaciones tributarias.

La actividad económica y la política tributaria son elementos que sobresalen en la definición y la estructura de todo sistema tributario. La actividad económica (como motor de generación, empleo y transformación de recursos) suministra una primera aproximación de la capacidad contributiva del agente económico para asumir una carga tributaria. La política tributaria, en cambio, establece el cálculo del impuesto; es decir, norma el hecho generador, el sujeto pasivo, el tipo impositivo, las exenciones y deducciones correspondientes y la liquidación del impuesto (Martín, 2009).

El cumplimiento de las obligaciones tributarias es un aspecto altamente considerado en el establecimiento de estrategias y medidas de control de la administración tributaria. Las acciones de control y gestión, ya sean masivas o intensivas, se diseñan de acuerdo con el impuesto recaudado, la brecha tributaria, el riesgo tributario y el segmento de contribuyentes que muestra indicios de mal comportamiento².

Existen diversos factores que determinan el cumplimiento tributario y como tales afectan la eficiencia de la recaudación tributaria. Autores como Allingham y Sandmo (1972), Andreoni, Erard y Feinstein (1998), Myles (2000), Slemrod y Yitzhaki (2002), Sandmo (2005) y Torgler (2007) analizan desde el punto de vista teórico varios de ellos. Entre los principales factores, figuran la aversión al riesgo, la percepción del control tributario, la fortaleza institucional de la administración tributaria, los costos administrativos de la declaración del impuesto, la interacción entre el contribuyente y la administración tributaria, la complejidad de la legislación tributaria, la justicia tributaria, la moral tributaria y la dinámica social.

En la práctica, estas características son difíciles de medir debido a su índole social e institucional. Con frecuencia, es preciso realizar encuestas periódicas para recoger la opinión de la sociedad respecto de estas cuestiones. Sin embargo, esto demanda recursos valiosos para la administración tributaria. Además, puede ser necesaria la elaboración de investigaciones de campo que utilicen evaluación de impacto para analizar la incidencia de estas características en el cumplimiento tributario ${ }^{3}$.

Entre estas características, la aversión al riesgo es un factor importante para entender el comportamiento del contribuyente. El modelo de Allingham y Sandmo (1972), que ha servido de base para los diferentes análisis teóricos sobre evasión tributaria, sostiene que la evasión crecerá conforme disminuya la probabilidad de captura, la penalidad, el tipo impositivo y la aversión al riesgo

\footnotetext{
2 El riesgo tributario hace referencia a la probabilidad que tiene la administración tributaria de incurrir en pérdidas, o de que ocurra algún evento desfavorable, como consecuencia de un comportamiento inusual por parte de los contribuyentes.

3 En los últimos años, la literatura sobre evasión tributaria ha crecido de forma rápida a través de la evaluación de impacto, especialmente de los experimentos de campo. En términos generales, estas evaluaciones se centran en el cumplimiento del impuesto a la renta y el impuesto al valor agregado, así como en variables que se emplean para su declaración y balance contable (ingresos, ventas, deducciones y gastos). Básicamente, su diseño contempla el envío de cartas, cuestionarios o folletos a un grupo de contribuyentes de manera previa al cumplimiento de sus obligaciones tributarias. Por lo común, la información que se entrega se enfoca en temas disuasivos, asistencia al contribuyente, servicios públicos, normas sociales y moral. Walsh (2012) y Hallsworth (2014) hacen una descripción concisa de varias de estas evaluaciones. Para países en desarrollo, Ortega y Sanguinetti (2013), Pomeranz (2015) y Carrillo, Pomeranz y Singhal (2017) son algunas de las referencias de los experimentos más importantes.
} 
del contribuyente y aumente su ingreso (Cowell, 2004). En particular, los dos últimos puntos asocian el cumplimiento tributario de manera diferente con características propias del contribuyente como su percepción y su actividad económica. Existe información que evidencia que la aversión al riesgo varía en el tiempo y se comporta de manera procíclica (Sancak, Velloso y Xing, 2010). En otras palabras, los contribuyentes evaden menos cuando la economía está en auge, ya que en esa fase del ciclo les resulta menos atractivo correr el riesgo de incurrir en una conducta que les significaría una sanción para asegurar su rentabilidad; por lo contrario, en fases de recesión los contribuyentes evaden más, puesto que la escasez de recursos los obliga a tomar el riesgo y cometer el fraude. Además, el cumplimiento tributario tiene una relación positiva con el fortalecimiento institucional de los países y una relación negativa con la presión fiscal en la economía (Sancak, Velloso y Xing, 2010).

\section{Estrategia metodológica}

La construcción del balance estructural de las finanzas públicas para evaluar la discrecionalidad de la política fiscal ha sido un tema de amplia discusión en la literatura económica. En ese sentido, la Organización para la Cooperación y el Desarrollo Económicos (OCDE) y el Fondo Monetario Internacional (FMI) han establecido metodologías similares para estos indicadores: ambos organismos proponen estimar econométricamente las elasticidades de los componentes del ingreso fiscal y el gasto público respecto del producto interno bruto (PIB) para extraer el efecto del ciclo económico y, por diferencia, obtener la influencia de la política en el resultado global de las finanzas públicas ${ }^{4}$. La Dirección General Impositiva del Uruguay (DGl) utiliza esta metodología para conocer la eficiencia de la gestión del IVA en el país por su gran relación con los otros tributos (DGl, 2006).

Desde el ámbito tributario, tanto el FMI (véase Ebrill y otros (2001) o Keen (2013)) como la OCDE (2008) han planteado evaluar las políticas tributarias relacionadas con el IVA por medio de la metodología de C-Efficiency. Este índice es la división de la recaudación del IVA para el producto de la alícuota y el consumo, en términos nominales antes de impuestos (Keen, 2013). El C-Efficiency también se utiliza para comparar el IVA entre los diferentes países, como lo hace la OCDE en sus informes (véase OCDE, 2008).

Los índices de gestión tributaria del IVA y del IR propuestos en este documento se basan en la metodología de la OCDE (2008), el FMI (Ebrill y otros, 2001) y la DGl del Uruguay (DGl, 2006). Se utiliza la metodología del FMI y de la OCDE para estimar las elasticidades de los impuestos respecto del PIB (o sus bases imponibles) y luego se retira el efecto del ciclo económico. También se estima el impacto de las reformas tributarias para sustraerlo de la recaudación de cada impuesto. El componente remanente de este proceso se usa para medir la eficiencia conjunta de la administración tributaria, conforme los lineamientos teóricos antes expuestos.

La estimación del índice comprende básicamente tres etapas: i) desestacionalización, ii) estimación de las elasticidades de largo plazo de la recaudación respecto del PIB y iii) ajuste de la recaudación por ciclo económico. Estos pasos permiten estimar la gestión conjunta de la administración tributaria en la recaudación de los ingresos tributarios. La primera acción excluye los efectos estacionales de las variables tributarias, que son propios del sistema tributario o económico y pueden provocar efectos adversos en la estimación econométrica; la segunda captura la actividad económica inmersa en la generación de la base imponible de los impuestos, y la tercera extrae las fluctuaciones cíclicas de la base imponible con las elasticidades. Este último paso permite ajustar la recaudación por ciclo

\footnotetext{
4 En síntesis, la metodología del balance estructural comprende tres pasos: estimar la elasticidad de los componentes del ingreso total y el gasto primario respecto del PIB (o base imponible); ajustar los ingresos y gastos por el ciclo económico y, finalmente, restar el gasto primario ajustado y el pago de interés de los ingresos ajustados. Véase un mayor detalle en Fedelino, Ivanova y Horton (2009).
} 
económico y corregir la aversión al riesgo de los contribuyentes en distintas fases de crecimiento. La DGI del Uruguay realiza este mismo proceso, pero su estimación de la elasticidad presenta un problema de endogeneidad entre la base imponible y la recaudación. En esta propuesta, dicho problema se corrige mediante el estimador de mínimos cuadrados ordinarios dinámicos.

Este proceso metodológico permite construir indicadores de eficiencia recaudatoria de la administración tributaria a partir de la identificación de los impuestos por estudiar (IVA o IR), sus bases imponibles macroeconómicas (PIB o consumo) y las reformas que afectan su recaudación. Para esta propuesta no se requiere información de materias primas, producción o importaciones, entre otras variables a nivel de la industria, como los métodos revisados por Pecho, Sánchez y Peláez (2012); tampoco es necesario cuantificar los procesos, sus insumos o su nivel de tecnología para establecer la eficiencia (véase Alm y Duncan, 2014), lo que es difícil en las economías en desarrollo.

Para implementar esta metodología en el Ecuador se utilizan los datos trimestrales del período comprendido entre 1993 y 2014 de la recaudación del IVA de operaciones internas ${ }^{5}$, del impuesto a la renta, el PIB y el consumo, en dólares corrientes (o nominales). Las series tributarias se rezagaron en un período para hacer coincidir la fecha de recaudación con el período fiscal en que se generó la base imponible. Además, se usa el método X11-ARIMA para desestacionalizar las variables.

\section{Elasticidades de los impuestos}

Las elasticidades de largo plazo del IVA y del IR se estiman de manera separada a través de dos modelos econométricos. Estos modelos explican el comportamiento macroeconómico de la recaudación tributaria en función de su base imponible (variable directamente asociada con la actividad económica). En el caso del IVA se utiliza el consumo final como aproximación de la base imponible, mientras que en el caso del IR se emplea el PIB (véase Sevilla, 2004):

$$
\text { Impuesto }_{t}=\alpha+\beta_{B I}^{\text {Impuesto }} \cdot B I_{t}+\delta \cdot D_{t}+u_{t}
$$

Donde Impuesto $_{t}$ es el logaritmo de la recaudación del IVA o del IR, $B I_{t}$ es el logaritmo de la base imponible para cada tributo (consumo o PIB), $\alpha$ es una constante, $\beta_{B I}^{\text {Impuesto }}$ es la elasticidad del impuesto respecto de su base imponible, $D_{t}$ es un vector de variables ficticias (dummies) que controlan reformas o cambios estructurales, $\delta$ es el coeficiente asociado a las variables ficticias y $u_{t}$ es el residuo.

Como se explicó anteriormente, los agentes económicos pueden tratar de ajustar su base imponible declarada para pagar menos impuestos, en función de su nivel de aversión al riesgo y de la penalidad que anticipan en caso de que la administración tributaria detecte el fraude (Allingham y Sandmo, 1972). Este hecho genera problemas de endogeneidad en la estimación de la elasticidad por mínimos cuadrados ordinarios (ordinary least squares (OLS)). Por otra parte, según los manuales de cuentas nacionales, la construcción del PIB y la del consumo ya incluyen los impuestos que se generan.

Para eliminar este problema se utiliza el método de mínimos cuadrados ordinarios dinámicos (dynamic ordinary least squares (DOLS)), que modifica la estimación por OLS con la inclusión de rezagos y adelantos de la primera diferencia de las variables independientes, sin afectar el resto de los supuestos de Gauss-Markov. Además, esta técnica es asintóticamente equivalente al estimador de máxima verosimilitud de Johansen, con mayor eficiencia y rendimiento sobre muestras pequeñas. Hay que recalcar que este método solo se debe usar cuando las variables evidencian previamente una relación de cointegración (Stock y Watson, 1993).

\footnotetext{
5 Se utiliza el IVA de operaciones internas porque el SRI gestiona este ingreso tributario. Del IVA de importaciones se encarga el Servicio Nacional de Aduana del Ecuador.
} 
La validación estadística de la relación de cointegración se realizó con base en la metodología de Engle y Granger (1987). En el caso de series integradas de orden 1, esta metodología se centra en comprobar que las series en nivel tengan raíz unitaria, las series en primera diferencia no tengan raíz unitaria y la combinación lineal de las series en nivel no tenga raíz unitaria. La existencia de raíz unitaria se evaluó a través de los test de Dickey-Fuller y Phillips y Perron (véase Baum, 2005). Debido a que podían existir quiebres estructurales en las series económicas por la crisis financiera de 1999 en el Ecuador y el impacto de la crisis financiera internacional de 2008, también se utilizó la prueba de Clemente, Montañés y Reyes (1998). Los resultados de este proceso se detallan en el anexo 1.

La identificación de quiebres estructurales en el modelo se hizo mediante la prueba de CUSUMSQ, que permite determinar los períodos de mayor inestabilidad en los residuos del modelo (Hansen, 1992; Krämer, Ploberger y Alt, 1988). Además, se utilizó la prueba de Chow de manera recursiva para encontrar la fecha más probable que determina el quiebre en las variables (Greene, 1999). Con estas pruebas se halló que el IVA tiene un quiebre estructural en media y pendiente en el segundo trimestre de 1999. En el modelo de IR no se detectó ningún quiebre (véase el anexo 2).

En la ecuación (1) se incluyen también variables ficticias para aislar los cambios legales que afectaron la estructura del sistema tributario. Existe una amplia discusión sobre la forma de evidenciar el impacto de estos cambios legales en la literatura de política fiscal (método narrativo). Entre las propuestas más relevantes están la inclusión de variables ficticias en el período vigente de la reforma, como hicieron Edelberg, Eichenbaum y Fisher (1999), y la utilización de las estimaciones ex ante de las reformas tributarias a partir de registros oficiales de acuerdo con Romer y Romer (2010). Esta última metodología ha recibido críticas por suponer cierta dinámica en las reformas, la cual probablemente estaría condicionada por la información, la vigencia de las reformas, el lapso entre el anuncio y la implementación, y las expectativas de los agentes económicos (Leeper, Walker y Yang, 2008; Perotti, 2007).

El Ecuador ha estado sujeto a reformas tributarias por diferentes motivos: económicos, institucionales o por choques exógenos. Arias y otros (2008), Paz y Miño Cepeda (2015) y Carvajal, Carrasco y Álvarez (2012) recogen la historia del sistema tributario en el país, en la que se presenta el contexto económico y político de los principales acontecimientos en la tributación ecuatoriana. Para el presente modelo se incluyen variables ficticias en el período de las reformas legales que modificaron la base imponible y/o la alícuota de manera permanente. En el caso del impuesto a la renta se consideraron seis reformas: i) entre diciembre de 1998 y diciembre de 1999 se sustituyó el IR por el impuesto a la circulación de capitales (ICC), con una tasa del 1\% a todo movimiento de dinero o capital en el marco de la Ley de Reordenamiento en Materia Económica en el Área Tributario-Financiera ${ }^{6}$, bajo el argumento de simplificaciones de trámites y eficiencia tributaria; ii) en enero de 2000 se restableció el impuesto a la renta, y el ICC se convirtió en un anticipo con una alícuota del 0,8\% hasta noviembre de 2000, cuando se lo eliminó completamente ${ }^{7}$, ya que el Fondo Monetario Internacional no estaba de acuerdo con esta medida; iii) en abril de 2007 se incrementó del 1\% al 2\% el porcentaje de retención del IR para las empresas que adquirieran bienes inmuebles o un contrato de servicios ${ }^{8}$, como parte de las primeras reformas del Presidente Rafael Correa; iv) en enero de 2008 se modificó el impuesto a la renta personal con una nueva tabla de imposición y la deducción de gastos personales, y un nuevo cálculo del anticipo del IR, con la perspectiva de mejorar la progresividad del tributo9; v) en diciembre de 2009 se instauró el anticipo como un impuesto mínimo y sin devolución en el marco de la Ley Reformatoria a la Ley de Régimen Tributario Interno y a la Ley Reformatoria para la Equidad Tributaria del Ecuador,

6 Ley de Reordenamiento en Materia Económica en el Área Tributario-Financiera (Ley Nº 98-17), publicada en el Registro Oficial $N^{0} 78$, del 1 de diciembre de 1998.

7 Ley para la Reforma de las Finanzas Públicas (Ley № 99-24), publicada en el Registro Oficial № 181, del 30 de abril de 1999.

8 Registro Oficial N 98, del 5 de junio de 2007.

9 Ley Reformatoria para la Equidad Tributaria del Ecuador, publicada en el Tercer Suplemento al Registro Oficial № 242, del 29 de diciembre de 2007. 
modificaciones que se realizaron por la aprobación de la Constitución de $2008^{10}$, y vi) en diciembre de 2010 se aprobó el Código Orgánico de la Producción, Comercio e Inversiones (COPCl), marco legal en el que se establecieron algunas deducciones y exenciones para la inversión en ciertos sectores productivos y ciertos activos, y se fijó una reducción de 1 punto porcentual en la alícuota del IR de las empresas cada año hasta llegar a un $22 \%$ en $2013^{11}$.

En el caso del IVA se consideraron cinco reformas que modificaron tanto la alícuota como la base imponible. La primera entró en vigor en diciembre de 1997 y en ella se reformó la lista de productos exentos de este impuesto indirecto ${ }^{12}$. La segunda fue el incremento de la tarifa del $10 \%$ al $12 \%$, como parte de las medidas para contrarrestar la crisis económica por la que atravesaba el país a finales de la década de 1990. La tercera fue el incremento temporal de la alícuota del IVA del $12 \%$ al $14 \%{ }^{13}$, que se eliminó debido a que no tuvo el apoyo político para mantenerla. La cuarta corresponde a las reformas realizadas con la Ley Reformatoria para la Equidad Tributaria del Ecuador respecto del IVA, en vigor desde enero de 2008, en las que se exonera de este tributo a las compras del sector público y se establece la devolución del impuesto a los exportadores, entre otras ${ }^{14}$. La última reforma considerada es la eliminación de las exoneraciones del IVA a las compras de las empresas públicas ${ }^{15}$.

\section{Construcción de los índices de eficiencia}

Con la estimación de la ecuación (1) se puede capturar la variación de los ingresos tributarios derivada de la evolución de la actividad económica. De acuerdo con los manuales del FMI (Ebrill y otros, 2001) y de la OCDE (2008), la recaudación se ajusta en función del ciclo económico con la siguiente expresión:

$$
\text { Impuesto }_{t}^{A}=\text { Impuesto }_{t}\left(\frac{B I_{t}^{T}}{B I_{t}}\right)^{\beta_{B I}^{I m p \text { pusto }}}
$$

Donde $\operatorname{Impuesto}_{t}^{A}$ es la recaudación ajustada del IVA o del IR por ciclo, $B I_{t}^{T}$ es la tendencia del consumo o el PIB y $\beta_{B I}^{\text {Impuesto }}$ es la elasticidad de largo plazo del impuesto respecto de su base. Este ajuste permite sustraer la relación procíclica de la aversión al riesgo del contribuyente, como se explicó antes. Si la elasticidad es mayor que 1, la ecuación (2) establece que una base imponible mayor (menor) que su tendencia genera una recaudación ajustada por debajo (por encima) de la recaudación observada, es decir:

$$
\begin{aligned}
& B I_{t}>B I_{t}^{T} \Rightarrow \text { Impuesto }_{t}^{A}<\text { Impuesto }_{t} \\
& B I_{t}<B I_{t}^{T} \Rightarrow \text { Impuesto }_{t}^{A}>\text { Impuesto }_{t}
\end{aligned}
$$

En otras palabras, la recaudación tributaria es castigada en períodos de auge y compensada en períodos de recesión. Esto permite extraer las variaciones características del ciclo económico y corregir el sesgo subyacente que introduce una menor (mayor) disposición a tomar riesgos en fases de expansión (represión) económica. Por último, con la finalidad de obtener una medición de la presión tributaria producto de la gestión de la administración tributaria, la recaudación ajustada se expresa en términos relativos a la base imponible real de largo plazo, tomando un año base. En este trabajo se consideró 2000 como año de referencia.

\footnotetext{
${ }^{10}$ Ley Reformatoria a la Ley de Régimen Tributario Interno y a la Ley Reformatoria para la Equidad Tributaria del Ecuador, publicada en el Suplemento al Registro Oficial № 94, del 23 de diciembre de 2009.

${ }^{11}$ Código Orgánico de la Producción, Comercio e Inversiones, publicado en el Primer Suplemento al Registro Oficial № 351, del 29 de diciembre de 2010.

12 Ley No 41, publicada en el Registro Oficial № 206, del 2 de diciembre de 1997.

${ }^{13}$ Suplemento al Registro Oficial № 390, del 15 de agosto de 2001.

${ }^{14}$ Ley Reformatoria para la Equidad Tributaria del Ecuador, publicada en el Tercer Suplemento al Registro Oficial № 242, del 29 de diciembre de 2007.

${ }^{15}$ Ley Orgánica de Empresas Públicas, publicada en el Primer Suplemento al Registro Oficial № 48, del 16 de octubre de 2009.
} 


\section{Estructura tributaria en el Ecuador}

El Ecuador es un país latinoamericano en desarrollo con una economía pequeña y abierta. Su sistema productivo es primario exportador, y en mayor medida desde el primer auge petrolero de la década de 1970. De acuerdo con Díaz (2018), el crecimiento económico promedio fue del 4\% anual entre 1972 y 2015 ; además, el autor menciona que el PIB per cápita se incrementó anualmente un 1,7\% en ese mismo período. Estas cifras están por debajo del desarrollo económico de la región. Se debe recalcar también que el país tiene una dependencia del comercio internacional, con el precio del petróleo como canal de transmisión.

Diferentes acontecimientos políticos, económicos y naturales llevaron al país a una crisis en 1999, caracterizada por una persistente tasa de inflación (el promedio entre 1990 y 1999 fue del 39,8\%), la desconfianza en el sistema monetario y más del $50 \%$ de la población en situación de pobreza. Las autoridades tomaron la decisión política de dolarizar la economía ecuatoriana. Esta medida tuvo resultados pocos años después, cuando se registró una tasa de inflación de un dígito (desde 2003) y un incremento del $4,3 \%$ del PIB real entre 2000 y 2006. A partir de 2007, el país experimentó un crecimiento económico del 3,9\%, en especial por el auge de los productos básicos que tuvo lugar en toda América Latina (Díaz, 2018).

Una desventaja que ha conllevado la dolarización es la eliminación de los instrumentos tradicionales de la política monetaria y cambiaria, que ha dejado toda la responsabilidad de la estabilidad macroeconómica a la políica fiscal. Justamente, esta última fue más dinámica desde 2007, tanto desde el lado de los ingresos como de los gastos. El Gobierno incrementó el gasto corriente y de capital en su afán de acelerar el desarrollo del país. A continuación, se presenta la evolución de los ingresos fiscales, en especial los tributarios, en el contexto de la metodología propuesta en el documento ${ }^{16}$.

Desde los años noventa, los ingresos petroleros y tributarios han sido la principal fuente de financiamiento (sobre la línea) del gasto público. En esta década, ambos ingresos representaron más del 90\% del total: en promedio, su participación fue del $43 \%$ y del 50\%, respectivamente. Con la creación del SRI en 1997, los ingresos tributarios se fortalecieron y alcanzaron una participación promedio del $59 \%$ hasta 2006. A partir de las reformas y la reorganización de la gestión tributaria que tuvieron lugar desde 2007, la contribución de los impuestos siguió aumentando, hasta alcanzar en promedio el $62 \%$ del total de ingresos en el período 2007-2015 (véase el gráfico 1).

La Constitución de la República del Ecuador estipula, en el artículo 300, que el régimen tributario debe regirse por los principios de generalidad, progresividad, eficiencia, simplicidad administrativa, irretroactividad, equidad, transparencia y suficiencia recaudatoria (Ecuador, 2008). Además, el Plan Nacional para el Buen Vivir contempla la necesidad de incrementar los ingresos del Estado, principalmente los tributarios, mediante el aumento de la cantidad de contribuyentes y de los controles y sanciones de la evasión (SENPLADES, 2009). En este sentido, el SRI ha desarrollado una estrategia de presión hacia abajo que abarca medidas como facilitar los procesos de declaración de impuestos a los contribuyentes que estén dispuestos a cumplir, brindar ayuda para realizar la declaración de impuestos, disuadir por detección a los contribuyentes que están dispuestos a cumplir si son presionados y usar toda la fuerza de la ley contra aquellos que han decidido no cumplir (Carvajal, Carrasco y Álvarez, 2012; Andino, Carrasco y Arteaga, 2012).

\footnotetext{
${ }^{16}$ Véase una revisión en mayor detalle de la política fiscal en el Ecuador en Carrillo (2017); Cueva, Mosquera y Ortiz (2018) y Almeida y otros (2012).
} 


\section{Gráfico 1}

Participación de los ingresos del gobierno central, 1990-2015

(En porcentajes)

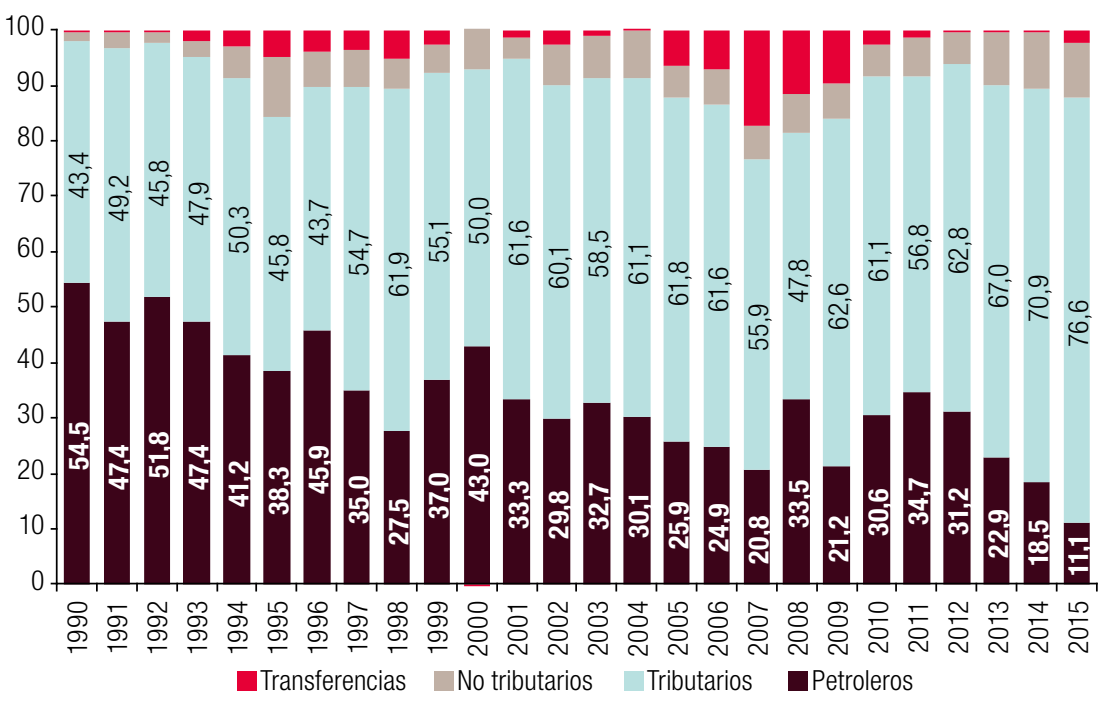

Fuente: Elaboración propia, sobre la base de información del Banco Central del Ecuador (BCE).

Nota: A partir de 2010 los datos corresponden al Presupuesto General del Estado (PGE) y no son comparables con los anteriores, porque se incorporan los datos de las entidades autónomas.

Los impuestos más representativos del Ecuador han sido el IVA y el IR. Entre 1993 y 2015, estos tributos han representado más del $80 \%$ de la recaudación efectiva, siendo el IVA el de mayor peso. No obstante, desde la entrada en vigor de la Constitución de 2008 el impuesto a la renta se ha fortalecido con una tabla de imposición más progresiva, retenciones y anticipos más altos, focalización de incentivos y beneficios, y mayores controles tributarios, entre otras medidas que lo han llevado a representar, en promedio, el 32\% de la recaudación efectiva entre 2009 y 2015 (véase el gráfico 2).

Gráfico 2

Participación de los impuestos en la recaudación efectiva, 1993-2015 (En porcentajes)

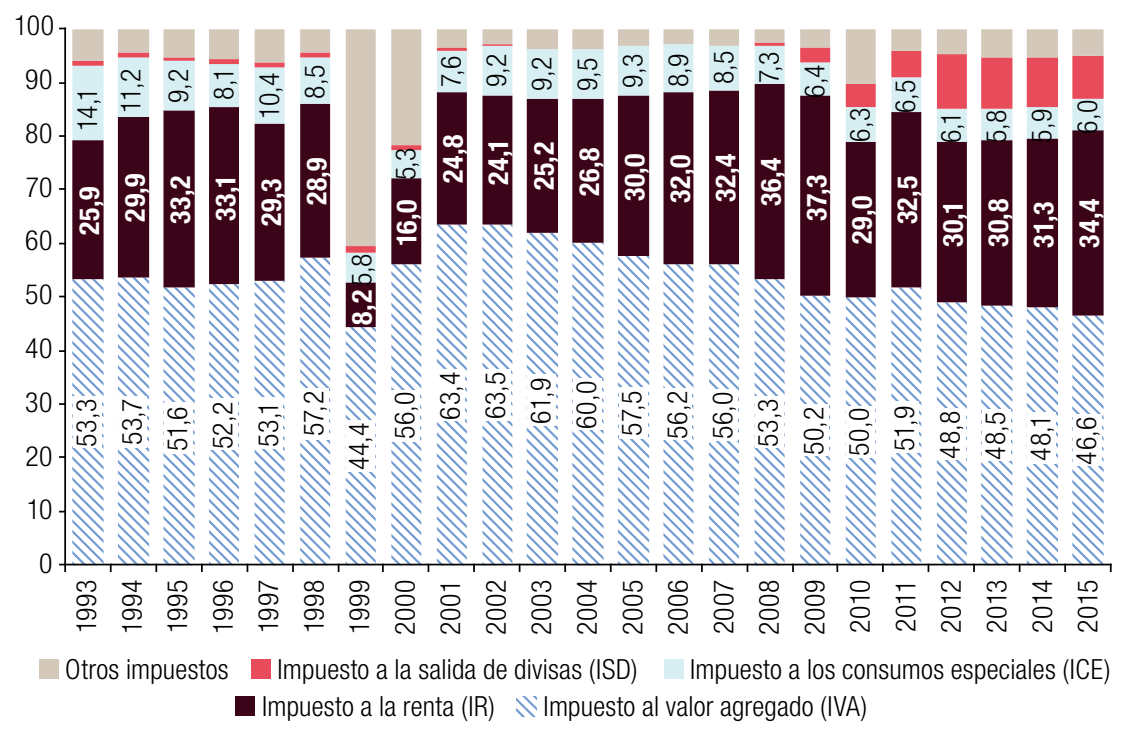

Fuente: Elaboración propia, sobre la base de información del Servicio de Rentas Internas (SRI).

Nota: $\quad$ En 1999 y 2000 se reemplazó el IR por el impuesto a la circulación de capitales (ICC). La recaudación registrada del ISD para los años anteriores a 2008 es la que se obtuvo en los aeropuertos por salida del país. 
En los últimos años, el incremento de la recaudación de estos impuestos ha sido fuerte y sostenido (véase el gráfico 3). Es probable que parte de este crecimiento se deba a la mejor gestión fiscal del SRI. Sin embargo, existen otros factores, como la actividad económica o las reformas tributarias realizadas últimamente, que pueden influir sobre el crecimiento tributario. Estos factores impiden precisar hasta qué grado el incremento de la recaudación es producto de la acción de la administración tributaria, o una consecuencia del proceso de reformas o de la evolución de la economía. Es aquí donde los indicadores de eficiencia propuestos ayudarán a medir el efecto de la gestión tributaria.

Gráfico 3

Recaudación por impuestos, 2003-2015

(En millones de dólares nominales)

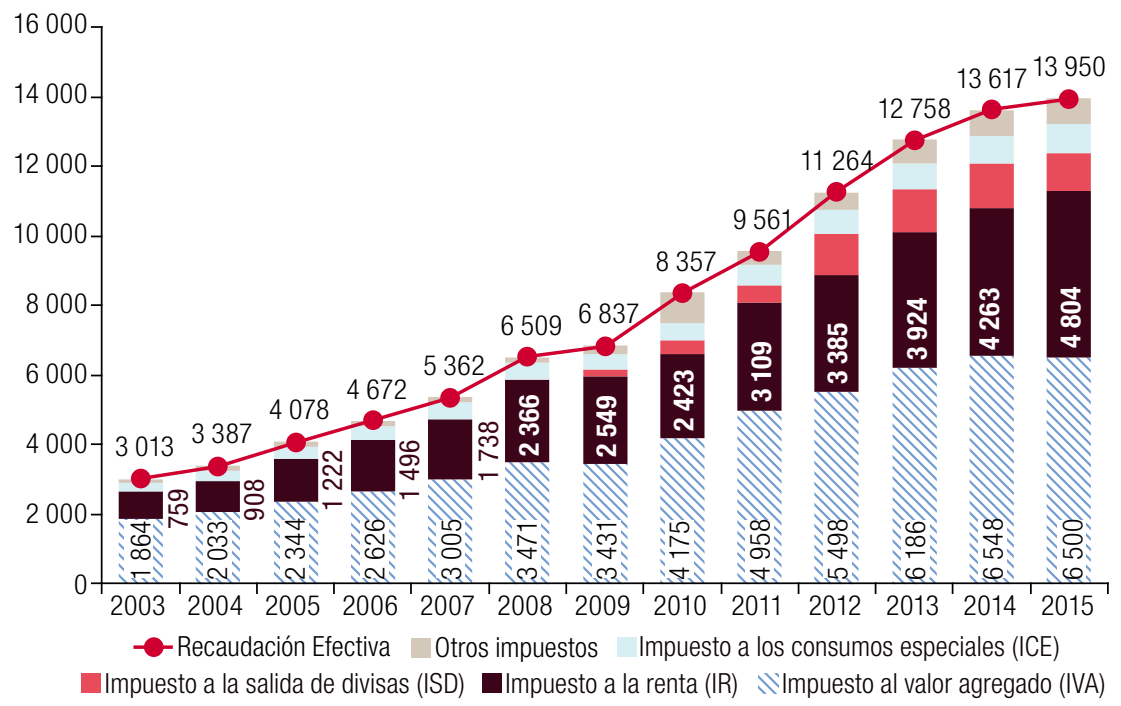

Fuente: Elaboración propia, sobre la base de información del Servicio de Rentas Internas (SRI).

\section{Eficiencia de la administración tributaria}

En esta sección se muestran los resultados de la aplicación en el Ecuador de la metodología presentada anteriormente. En primera instancia se expone la estimación de la elasticidad de los tributos y se compara el resultado con los obtenidos en otros trabajos que también han estimado estos coeficientes en la región. En segundo lugar, se exhiben los índices con periodicidad anual para el período de dolarización. Los índices trimestrales se pueden revisar en el anexo 3.

Para el Ecuador, la elasticidad del IVA respecto del consumo es 1,9505 con una significancia al 99\%. Como ya se mencionó, se detectó un quiebre estructural en el segundo trimestre de 1999, que muestra una elasticidad menor: 0,4856 (1,9505-1,4649). En otras palabras, el comportamiento del IVA antes del quiebre fue menos elástico con relación al consumo. El IR tiene una elasticidad de 2,6669 respecto del PIB con una significancia al 99\% (véase el cuadro 1).

El cálculo de las elasticidades de los impuestos es extenso en la literatura económica. América Latina no ha sido la excepción. El cuadro 2 muestra las elasticidades de largo plazo del IVA y del IR en países de América Latina estimadas por Ardanaz y otros (2015). Allí, el Ecuador muestra elasticidades de 2,0 y 2,3 para el IVA y el IR, respectivamente, valores cercanos a las estimaciones realizadas en el presente trabajo, lo que confirma la posición del país por encima del promedio regional con impuestos más elásticos. 


\section{Cuadro 1}

Ecuador: estimación mediante el método de mínimos cuadrados ordinarios dinámicos (DOLS) de las elasticidades de largo plazo del impuesto al valor agregado (IVA)

y el impuesto a la renta (IR)

\begin{tabular}{|c|c|c|c|c|c|}
\hline Variable & Coeficiente & P valor & Variable & Coeficiente & P valor \\
\hline Constante & $-18,5125^{\star \star \star}$ & 0,0000 & Constante & $-30,9628^{\star \star *}$ & 0,0000 \\
\hline Elasticidad IVA-Consumo & $1,9505^{\star \star \star}$ & 0,0000 & Elasticidad IR-PIB & $2,6669^{\star \star \star}$ & 0,0000 \\
\hline Quiebre media & $22,6490^{\star *}$ & 0,0175 & & & \\
\hline Quiebre pendiente & $-1,4649^{\star \star}$ & 0,0160 & & & \\
\hline
\end{tabular}

Fuente: Elaboración propia.

Nota: $\quad{ }^{\star \star \star} p<0,01,{ }^{\star \star} p<0,05,{ }^{*} p<0,1$.

\section{Cuadro 2}

América Latina (20 países): elasticidades de largo plazo del impuesto al valor agregado (IVA) y el impuesto a la renta (IR)

\begin{tabular}{llc}
\hline País & $\mathbb{R}$ & Impuestos indirectos \\
\hline Argentina & 3,0 & 1,1 \\
\hline Barbados & 1,9 & 1,7 \\
\hline Bolivia (Estado Plurinacional de) & 3,0 & 1,5 \\
\hline Brasil & 2,3 & 1,0 \\
\hline Chile & 1,2 & 1,4 \\
\hline Colombia & 1,3 & 1,8 \\
\hline Costa Rica & 2,0 & 0,8 \\
\hline Ecuador & 2,3 & 2,0 \\
\hline El Salvador & 3,0 & 2,1 \\
\hline Guatemala & 2,2 & 2,0 \\
\hline Guyana & 1,6 & 1,8 \\
\hline Honduras & 1,4 & 3,1 \\
\hline México & 1,3 & 1,8 \\
\hline Panamá & 1,3 & 0,7 \\
\hline Paraguay & 0,5 & 2,1 \\
\hline Perú & 2,0 & 1,8 \\
\hline República Dominicana & 1,8 & 1,4 \\
\hline Trinidad y Tabago & 0,6 & 0,7 \\
\hline Uruguay & 2,5 & 3,8 \\
\hline Venezuela (República Bolivariana de) & 3,3 & 2,6 \\
\hline América Latina (promedio) & 1,9 & 1,8 \\
\hline
\end{tabular}

Fuente: M. Ardanaz y otros, "Structural fiscal balances in Latin America and the Caribbean: new dataset and estimations", IDB Working Paper, N ${ }^{\circ}$ 579, Washington, D.C., Banco Interamericano de Desarrollo (BID), junio de 2015.

Nota: La elasticidad del IR es el promedio simple de la elasticidad del impuesto a la renta de las empresas y de las personas naturales. Los impuestos indirectos corresponden a la suma del IVA y los impuestos especiales.

Con la estimación de las elasticidades, las series tributarias se ajustaron por el ciclo económico mediante la ecuación (2). Este mismo procedimiento ajusta también la aversión al riesgo que presentan los contribuyentes en lo referente a la evasión de impuestos, ya que, si el ciclo está por encima de su tendencia (auge), los agentes evaden menos debido a la generación creciente de recursos económicos, mientras que en fases de recesión los contribuyentes evaden más porque sus ingresos se reducen.

El indicador del IVA permite distinguir tres períodos (véase el gráfico 4). Durante el primer período, comprendido entre 2000 y 2002, el SRI tuvo un comportamiento pasivo respecto de la recaudación de este impuesto. En el segundo período, entre 2003 y 2006, se evidencia una disminución del indicador por debajo del nivel correspondiente al año base. Andino y Parra (2007) muestran que la evasión en el caso del IVA pasó del 30,1\% al 31,8\% entre 2003 y 2005. Este hecho se podría vincular con la destitución del Presidente Lucio Gutiérrez y la crisis política e institucional por la que atravesó el país. 


\section{Gráfico 4}

Promedio anual del indicador de eficiencia del impuesto al valor agregado (IVA), 2000-2014 (Índice, año base $2000=100$ )

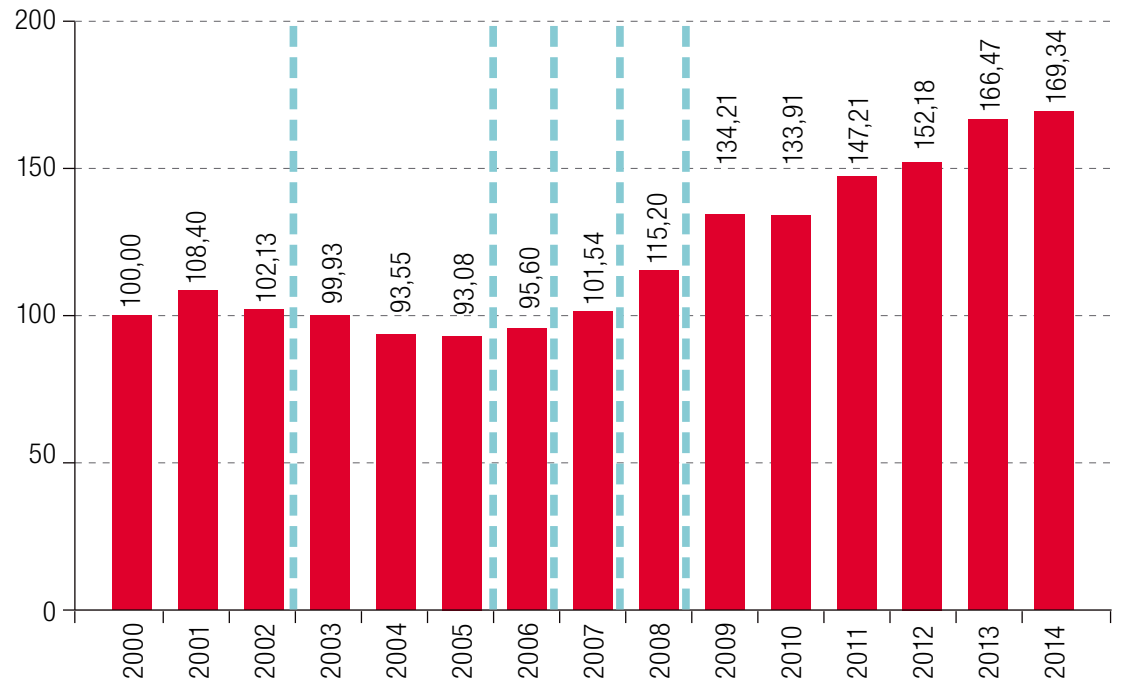

Fuente: Elaboración propia.

Nota: Las líneas entrecortadas representan las reformas institucionales al Reglamento Orgánico Funcional del Servicio de Rentas Internas (SRI) realizadas en octubre de 2002, junio de 2005, junio de 2006, noviembre de 2006, abril de 2007 y enero de 2008 (Carvajal, Carrasco y Álvarez, 2012).

En el tercer período, que se inicia en 2007, el SRI realizó varias mejoras administrativas y operativas (anexos y cruces de información, capacitación y formación (véase Carvajal, Carrasco y Álvarez, 2012; Andino, Carrasco y Arteaga, 2012)) que permitieron aumentar la eficiencia en la recaudación del IVA de forma progresiva. En 2010, solo se observa una pequeña caída de la eficiencia (véase el gráfico 4), probablemente como anticipación a las reformas legales del Código Orgánico de la Producción, Comercio e Inversiones (COPCI) aprobado a finales de ese año, que establecía varias exenciones y deducciones al sector productivo. Se puede argumentar que el constante crecimiento ocurrido desde 2007 se debe a las mejoras en información complementaria, como el Anexo de Gastos Personales y la Lotería Tributaria, entre otras, que podrían haber afectado la cultura tributaria de los contribuyentes.

El índice de eficiencia recaudatoria del IR se presenta en el gráfico 5. Este indicador muestra un crecimiento moderado en los primeros cinco años de dolarización (29,8 puntos). En 2001, el indicador evidencia una mejora significativa en la gestión del SRI provocada, principalmente, por el restablecimiento del impuesto a la renta, su control y la eliminación del impuesto a la circulación de capitales (ICC). Es preciso aclarar que en la estimación del índice ya se controla por las reformas de la sustitución del IR por el ICC, pero es probable que el restablecimiento del primer tributo tenga un efecto indirecto en el control que no estaría dado por los cambios legales.

Entre 2004 y 2009, el índice experimenta una notoria aceleración de crecimiento (59,8 puntos), posiblemente a causa de la innovación en los procesos de control y servicios. La administración tributaria incorporó nueva tecnología para fortalecer el control tributario, como los servicios en línea o la facturación electrónica (Carvajal, Carrasco y Álvarez, 2012; Andino, Carrasco y Arteaga, 2012). Además, la nueva dirección administrativa del SRI mantuvo la misma línea política en torno a la imposición directa, como lo dictamina la Constitución del Ecuador (Carrasco, 2012).

En 2009 se produce una disminución de la eficiencia recaudatoria del impuesto a la renta, probablemente porque la administración tributaria anticipa una posible evasión de los contribuyentes, ya que sus ingresos disminuirían a consecuencia de la crisis financiera mundial. En adelante, el SRI retoma su eficiencia recaudatoria y el índice propuesto pasa de 208,6 puntos en 2010 a 279,8 puntos en 2014. 


\section{Gráfico 5}

Promedio anual del indicador de eficiencia del impuesto a la renta (IR), 2000-2014

(Índice, año base $2000=100$ )

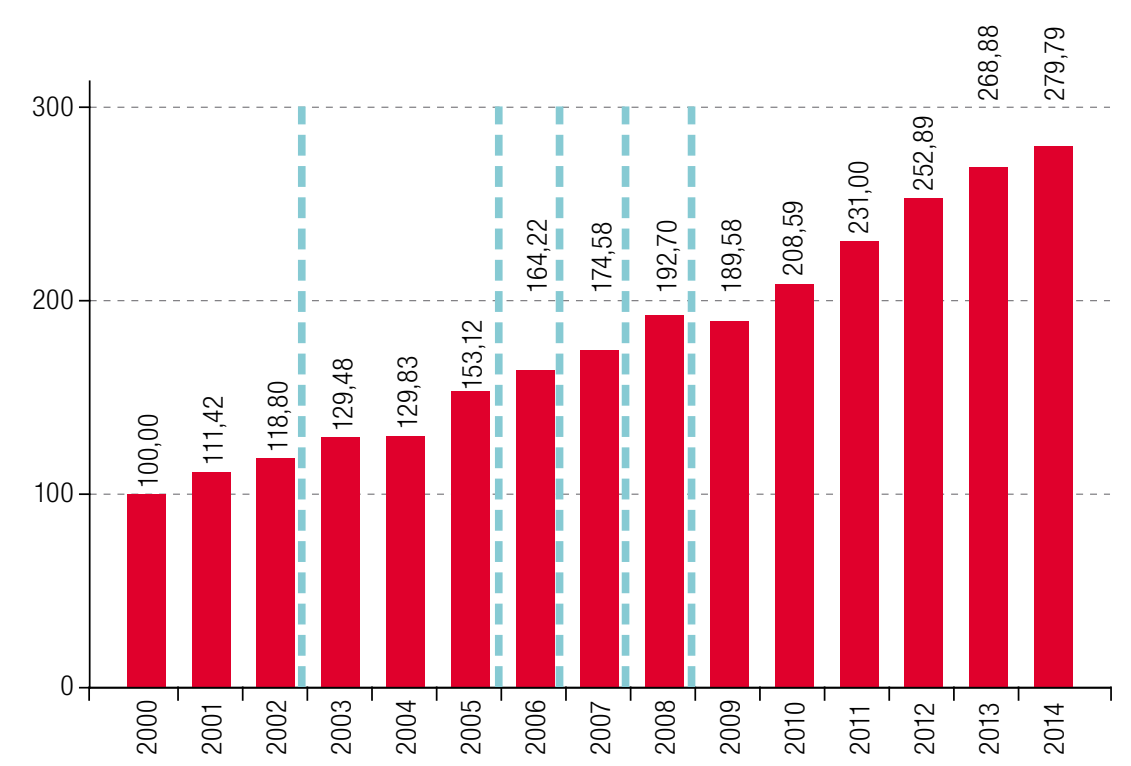

Fuente: Elaboración propia.

Nota: Las líneas entrecortadas representan las reformas institucionales al Reglamento Orgánico Funcional del Servicio de Rentas Internas (SRI) realizadas en octubre de 2002, junio de 2005, junio de 2006, noviembre de 2006, abril de 2007 y enero de 2008 (Carvajal, Carrasco y Álvarez, 2012).

En resumen, los índices de eficiencia recaudatoria utilizados en este trabajo muestran tres comportamientos diferenciados de la administración tributaria. El primero es un comportamiento pasivo del SRI: en el caso del IVA, tal comportamiento se observó entre 2000 y 2006, mientras que en el caso del IR se observó entre 2000 y 2004. El segundo es un comportamiento de eficiencia creciente, que influyó en la recaudación a raíz de la puesta en marcha de reformas administrativas en el SRI: para el IVA este período comienza en 2007 y para el IR en 2005. El último comportamiento lo constituyen las caídas puntuales en la eficiencia de la administración tributaria, que podrían tener su origen en fenómenos exógenos a la propia administración como choques internacionales o efectos indirectos de las reformas legales, que merman la base imponible y, por ende, la recaudación.

Además, se evidencia que las reformas que buscaron fortalecer la institucionalidad del SRI (excepto la de 2002) lograron mejorar su gestión tributaria. Los índices del IR y del IVA exponen con claridad ese efecto, con incrementos del 48\% y el 43\%, respectivamente, entre 2004 y 2008.

\section{Conclusiones}

En el ámbito tributario, la búsqueda de mayor eficiencia persigue el cierre de las brechas tributarias mediante acciones que emprende la administración tributaria para incrementar la recaudación de impuestos. El logro de mayor eficiencia tributaria es de vital importancia, pues permite generar recursos suficientes y oportunos para sostener la ejecución del gasto público en el largo plazo.

Si bien la administración tributaria cuenta con información para medir ciertas brechas, se requiere información externa para estimar de manera continua su gestión y su efectividad. El presente trabajo propone la construcción de un indicador de eficiencia recaudatoria a partir de información macroeconómica de fácil acceso. Con base en la metodología del balance estructural de las finanzas públicas, este indicador se 
estima para el IVA y el IR del Ecuador entre 1993 y 2014. Este indicador pretende ser un instrumento de seguimiento de la actividad recaudatoria y fiscalizadora del SRI en el cierre conjunto de las brechas tributarias. Para su construcción, la idea principal es filtrar el efecto de las reformas tributarias, las fluctuaciones del ciclo económico y la aversión al riesgo que afectan la recaudación de los principales impuestos en el país.

Los resultados muestran que la gestión del SRI ha mejorado la eficiencia de la recaudación del IVA y del IR en la última década. Además, se evidencia una recuperación de la eficiencia en la recaudación del IVA desde 2007, en tanto que la eficiencia en la recaudación del IR exhibe un crecimiento sostenido prácticamente en todo el período de estudio, con variaciones importantes entre 2005 y 2010. Por último, se puede atribuir a la administración tributaria un cierto comportamiento adaptativo a la posible disminución de la recaudación por diferentes motivos (choques externos o reformas legales que amplían las deducciones o exenciones).

\section{Bibliografía}

Allingham, M. y A. Sandmo (1972), "Income tax evasion: a theoretical analysis", Journal of Public Economics, vol. 1, No 3-4, noviembre.

Alm, J. y D. Duncan (2014), "Estimating tax agency efficiency", Public Budgeting \& Finance, vol. 34, № 3.

Almeida, M. y otros (2012), "Ingresos y gasto público en democracia: de la rigidez fiscal al pago de la deuda social", Una nueva política fiscal para el buen vivir: la equidad como soporte del pacto fiscal, Servicio de Rentas Internas (SRI), Quito, Ediciones Abya-Yala.

Andino, M. y J. Parra (2007), "Estimación de la brecha de recaudación del IVA e impuesto a la renta de las sociedades por industria", Revista Fiscalidad, № 1, Quito, Servicio de Rentas Internas (SRI).

Andino, M., C. Carrasco y L. Arteaga (2012), "Servicio de Rentas Internas: repensando el nuevo modelo organizacional y de gestión", Una nueva política fiscal para el buen vivir: la equidad como soporte del pacto fiscal, Servicio de Rentas Internas (SRI), Quito, Ediciones Abya-Yala.

Andreoni, J., B. Erard y J. Feinstein (1998), "Tax compliance”, Journal of Economic Literature, vol. 36, № 2, junio.

Ardanaz, M. y otros (2015), "Structural fiscal balances in Latin America and the Caribbean: new dataset and estimations", IDB Working Paper, № 579, Washington, D.C., Banco Interamericano de Desarrollo (BID), junio.

Arias, D. y otros (2008), "Historia del sistema tributario ecuatoriano 1950-1999", Revista Fiscalidad, № 2 , Quito, Servicio de Rentas Internas (SRI).

Baum, C. (2005), "Stata: the language of choice for time series analysis?", The Stata Journal, vol. 5, № 1.

Carrasco, C. (2012), "Introducción", Una nueva política fiscal para el buen vivir: la equidad como soporte del pacto fiscal, Servicio de Rentas Internas (SRI), Quito, Ediciones Abya-Yala.

Carrillo, P. (2017), "El efecto de la política fiscal en expansión y recesión para Ecuador: un modelo MSVAR", Cuadernos de Economía, vol. 36, № 71, Bogotá, Universidad Nacional de Colombia.

Carrillo, P., D. Pomeranz y M. Singhal (2017), "Dodging the taxman: firm misreporting and limits to tax enforcement", American Economic Journal: Applied Economics, vol. 9, № 2, abril.

Carvajal, D., C. Carrasco y J. Álvarez (2012), "Historia de la tributación en Ecuador: cambios sociales y organizacionales", Una nueva política fiscal para el buen vivir: la equidad como soporte del pacto fiscal, Servicio de Rentas Internas (SRI), Quito, Ediciones Abya-Yala.

Clemente, J., A. Montañés y M. Reyes (1998), "Testing for a unit root in variables with a double change in the mean", Economics Letters, vol. 59, Nㅜㄹ. mayo.

Cowell, F. (2004), "Carrots and sticks in enforcement", The Crisis in Tax Administration, H. Aaron y J. Slemrod (eds.), Washington, D.C., Brookings Institution Press.

Cueva, S., R. Mosquera y M. Ortiz (2018), "Ciclicalidad de la política fiscal ecuatoriana desde la dolarización", Reformas y desarrollo en el Ecuador contemporáneo, J. Díaz-Cassou y M. Ruiz Arranz (eds.), Washington, D.C., Banco Interamericano de Desarrollo (BID).

DGI (Dirección General Impositiva) (2006), "Eficiencia de la Administración Tributaria en la recaudación: ¿Contribuye la gestión de la DGl a incrementar la recaudación impositiva?", Documento de trabajo, № 4, julio.

Díaz, J. (2018), "La historia económica contemporánea de Ecuador, 1972-2015", Reformas y desarrollo en el Ecuador contemporáneo, J. Díaz-Cassou y M. Ruiz Arranz (eds.), Washington, D.C., Banco Interamericano de Desarrollo (BID).

Ebrill, L. y otros (eds.) (2001), The Modern VAT, Washington, D.C., Fondo Monetario Internacional (FMI).

Ecuador (2008), Constitución de la República del Ecuador, Quito, Tribunal Constitucional, octubre. 
Edelberg, W., M. Eichenbaum y J. Fisher (1999), "Understanding the effects of a shock to government purchases", Review of Economic Dynamics, vol. 2, № 1.

Engle, R. y C. Granger (1987), "Co-integration and error correction: representation, estimation, and testing", Econometrica, vol. 55, N² 2, marzo.

Fedelino, A., A. Ivanova y M. Horton (2009), "Computing cyclically adjusted balances and automatic stabilizers", Technical Notes and Manuals, vol. 9, № 5, Washington, D.C., Fondo Monetario Internacional (FMI), noviembre.

Greene, W. (1999), Análisis econométrico, 3a edición, Madrid, Prentice Hall.

Hallsworth, M. (2014), "The use of field experiments to increase tax compliance", Oxford Review of Economic Policy, vol. 30, № 4.

Hansen, B. (1992), "Testing for parameter instability in linear models", Journal of Policy Modeling, vol. 14, $N^{\circ} 4$, agosto.

Jorratt, M. (1996), "Evaluación de la capacidad recaudatoria de un sistema tributario y de la evasión tributaria", documento presentado en la Conferencia Técnica del Centro Interamericano de Administraciones Tributarias (CIAT), Viterbo, octubre.

Keen, M. (2013), "The anatomy of the VAT", National Tax Journal, vol. 66, № 2, junio.

Krämer, W., W. Ploberger y R. Alt (1988), "Testing for structural change in dynamic models", Econometrica, vol. $56, N^{\circ} 6$.

Leeper, E., T. Walker y S. Yang (2008), "Fiscal foresight: analytics and econometrics", NBER Working Paper, № 14028, Cambridge, Oficina Nacional de Investigaciones Económicas (NBER), mayo.

Martín, F. (2009), "La economía de los ingresos tributarios: un manual de estimaciones tributarias", Serie Manuales, № 62 (LC/L.3047-P), Santiago, Comisión Económica para América Latina y el Caribe (CEPAL), agosto.

Myles, G. (2000), "Taxation and economic growth", Fiscal Studies, vol. 21, № 1, marzo.

OCDE (Organización de Cooperación y Desarrollo Económicos) (2008), Consumption Tax Trends 2008: VAT/ GST and Excise Rates, Trends and Administration Issues, París.

Ortega, D. y P. Sanguinetti (2013), "Deterrence and reciprocity effects on tax compliance: experimental evidence from Venezuela", CAF Documentos de Trabajo, № 2013/08, Caracas, Banco de Desarrollo de América Latina (CAF), diciembre.

Paz y Miño Cepeda, J. (2015), Historia de los impuestos en Ecuador: visión sobre el régimen impositivo en la historia económica nacional, Quito, Servicio de Rentas Internas (SRI).

Pecho, M., J. Sánchez y F. Peláez (2012), "Estimación del incumplimiento tributario en América Latina: 2000-2010", Documentos de Trabajo, №3, Panamá, Centro Interamericano de Administraciones Tributarias (CIAT), septiembre.

Perotti, R. (2007), "In search of the transmission mechanism of fiscal policy", NBER Working Paper, № 13143, Cambridge, Oficina Nacional de Investigaciones Económicas (NBER), junio.

Pomeranz, D. (2015), "No taxation without information: deterrence and self-enforcement in the value added tax", American Economic Review, vol. 105, № 8, agosto.

Ricciardi, M. (2007), "Análisis de eficiencia en el IVA y una propuesta para eliminar los impuestos distorsivos", documento preparado para el Segundo Congreso Metropolitano de Ciencias Económicas, Buenos Aires, noviembre.

Romer, C. y D. Romer (2010), "The macroeconomic effects of tax changes: estimates based on a new measure of fiscal shocks", American Economic Review, vol. 100, № 3, junio.

Sancak, C., R. Velloso y J. Xing (2010), "Tax revenue response to the business cycle", IMF Working Paper, $N^{\circ}$ WP/10/71, Washington, D.C., Fondo Monetario Internacional (FMI), marzo.

Sandmo, A. (2005), "The theory of tax evasion: a retrospective view", National Tax Journal, vol. 58, № 4.

SENPLADES (Secretaría Nacional de Planificación y Desarrollo) (2009), Plan Nacional para el Buen Vivir: 2009-2013: construyendo un Estado plurinacional e intercultural, Quito.

Sevilla, J. (2004), Política y técnica tributarias, Manuales de la Escuela de la Hacienda Pública, Madrid, Instituto de Estudios Fiscales (IEF).

Slemrod, J. y S. Yitzhaki (2002), "Tax avoidance, evasion, and administration", Handbook of Public Economics, vol. 3, A. Auerbach, M. Feldstein y E. Saez (eds.), Elsevier.

Stock, J. y M. Watson (1993), "A simple estimator of cointegrating vectors in higher order integrated systems", Econometrica, vol. 61, № 4, julio.

Torgler, B. (2007), Tax Compliance and Tax Morale: A Theoretical and Empirical Analysis, Cheltenham, Edward Elgar Publishing.

Walsh, K. (2012), "Understanding taxpayer behaviour - new opportunities for tax administration”, The Economic and Social Review, vol. 43, №3. 


\section{Anexo A1}

\section{Cuadro A1.1}

Pruebas de raíz unitaria de Clemente, Montañés y Reyes (CMD) para series en nivel, series en diferencias y perturbaciones del modelo

Series en nivel

H0: Las series tienen raíz unitaria

\begin{tabular}{lcrrr}
\hline \multirow{2}{*}{ Variable } & \multirow{2}{*}{ Estadístico T } & \multicolumn{3}{c}{ Valores críticos } \\
\cline { 3 - 5 } & & $\mathbf{1 \%}$ & $5 \%$ & $10 \%$ \\
\hline IVA & $-3,52$ & $-5,96$ & $-5,49$ & $-5,24$ \\
\hline Consumo & $-3,17$ & $-5,96$ & $-5,49$ & $-5,24$ \\
\hline IR & $-5,73$ & $-5,96$ & $-5,49$ & $-5,24$ \\
\hline PIB & $-2,39$ & $-5,96$ & $-5,49$ & $-5,24$ \\
\hline
\end{tabular}

Series en diferencias

HO: Las series tienen raíz unitaria

\begin{tabular}{lcrrr}
\hline \multirow{2}{*}{ Variable } & \multirow{2}{*}{ Estadístico T } & \multicolumn{3}{c}{ Valores críticos } \\
\cline { 3 - 5 } & & $1 \%$ & $5 \%$ & $10 \%$ \\
\hline IVA & $-6,40$ & $-5,96$ & $-5,49$ & $-5,24$ \\
\hline Consumo & $-8,38$ & $-5,96$ & $-5,49$ & $-5,24$ \\
\hline IR & $-7,56$ & $-5,96$ & $-5,49$ & $-5,24$ \\
\hline PIB & $-7,56$ & $-5,96$ & $-5,49$ & $-5,24$ \\
\hline
\end{tabular}

Perturbaciones

H0: Las series tienen raíz unitaria

\begin{tabular}{lcrrr}
\hline \multirow{2}{*}{ Variable } & \multirow{2}{*}{ Estadístico T } & \multicolumn{3}{c}{ Valores críticos } \\
\cline { 3 - 5 } & & $1 \%$ & $5 \%$ & $10 \%$ \\
\hline Error de IVA & $-14,56$ & $-5,96$ & $-5,49$ & $-5,24$ \\
\hline Error de IR & $-10,42$ & $-5,96$ & $-5,49$ & $-5,24$ \\
\hline
\end{tabular}

Fuente: Elaboración propia.

Nota: Si el estadístico T es menor que un valor crítico, entonces se acepta la hipótesis nula con el margen de error correspondiente a dicho valor crítico. 


\title{
Anexo A2
}

\author{
Gráfico A2.1
}

Pruebas de sumas acumulativas (CUSUMSQ) y prueba de Chow

A. Prueba CUSUMSQ - Modelo IVA

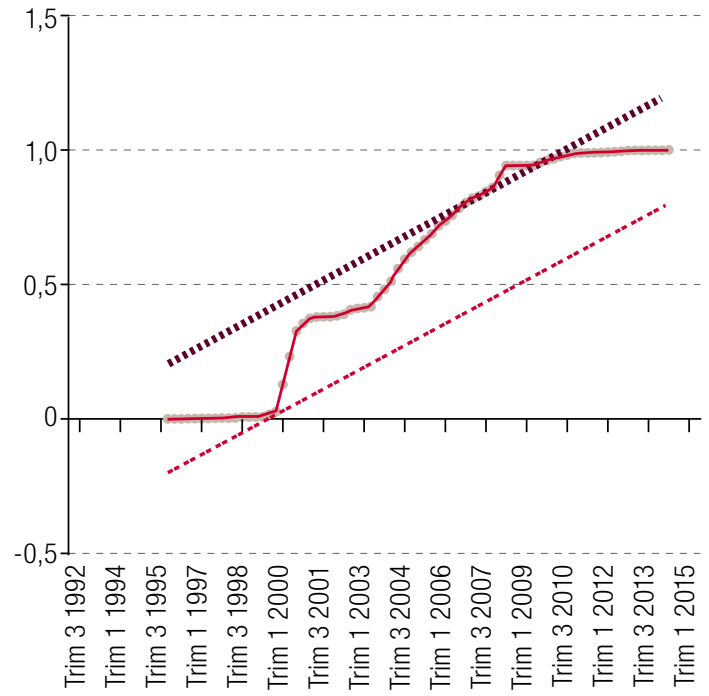

C. Prueba CUSUMSQ - Modelo IR

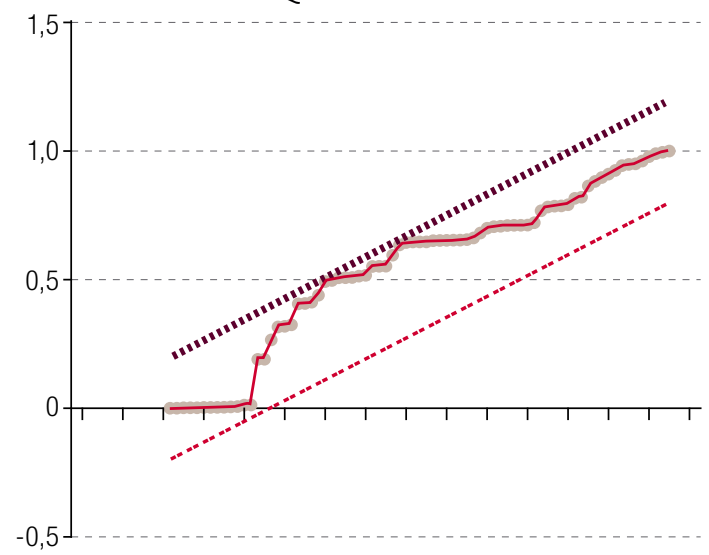

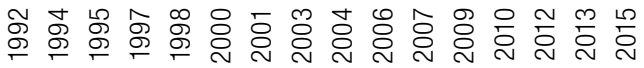
$m-m-m \sim m \sim m \sim m \sim m \sim m \sim$

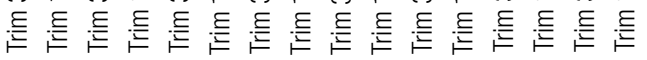

B. Prueba de Chow - Modelo IVA

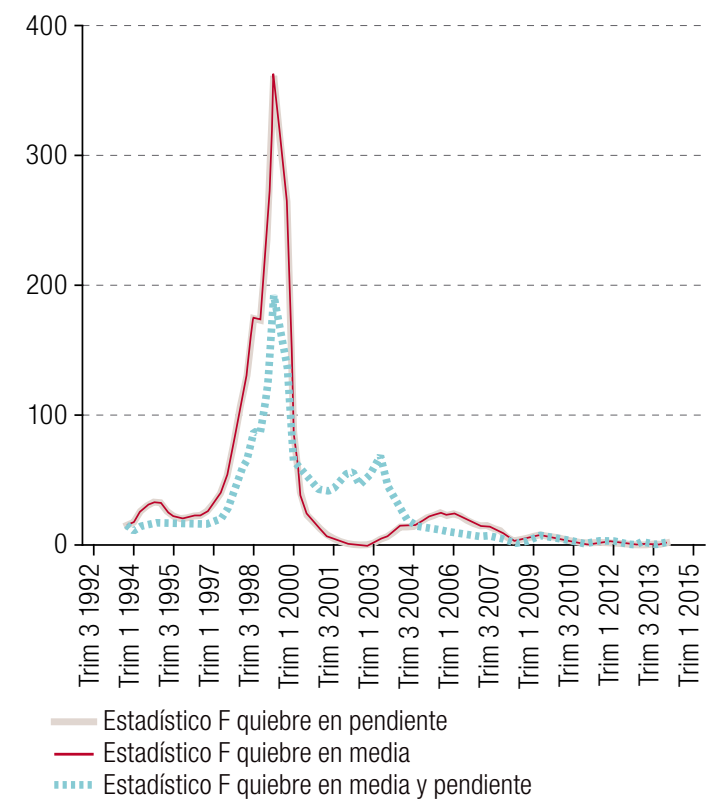

D. Prueba de Chow - Modelo IR

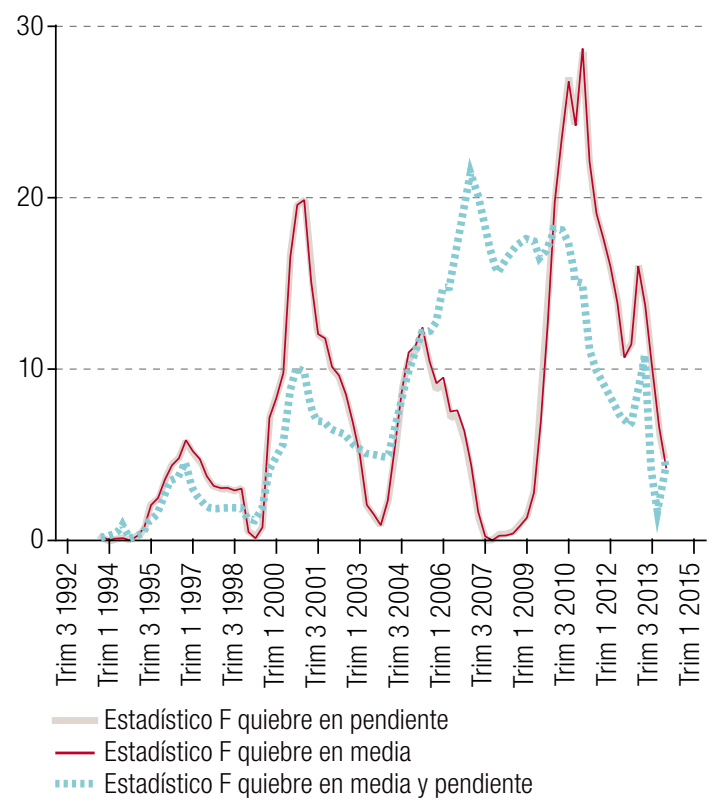

Fuente: Elaboración propia. 


\section{Anexo A3}

Gráfico A3.1

Índices trimestrales de eficiencia del impuesto al valor agregado (IVA) y del impuesto a la renta (IR) y crecimiento trimestral (Índice, año base $2000=100$ y en porcentajes)

A. Indicador de eficiencia del IVA

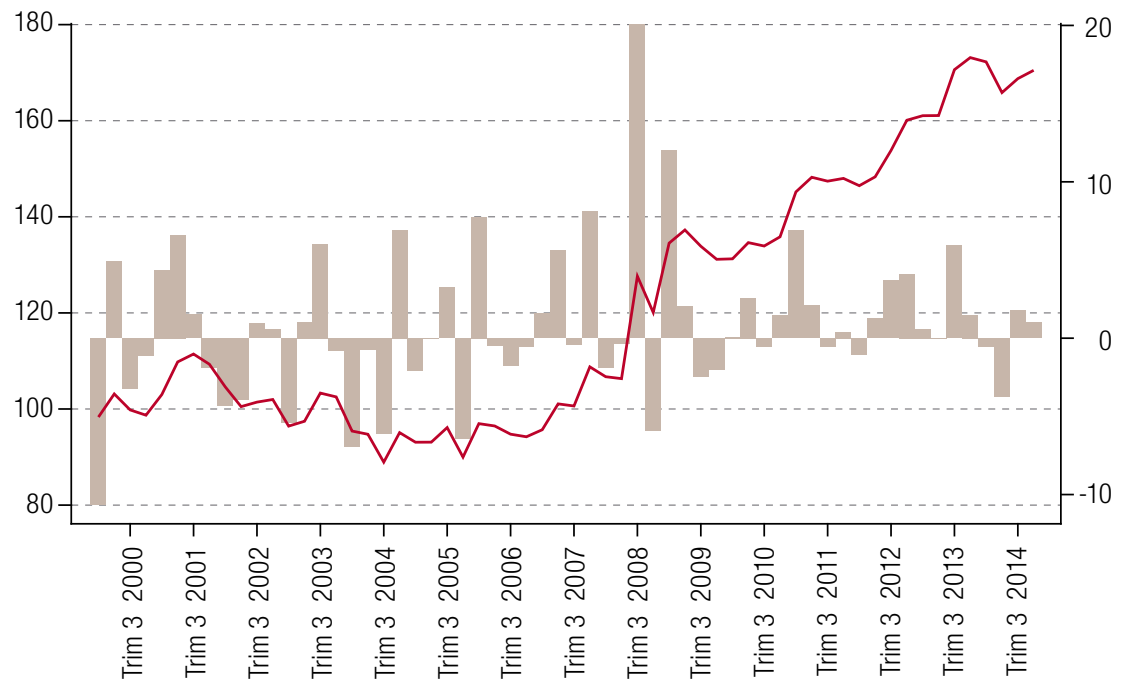

B. Indicador de eficiencia del IR

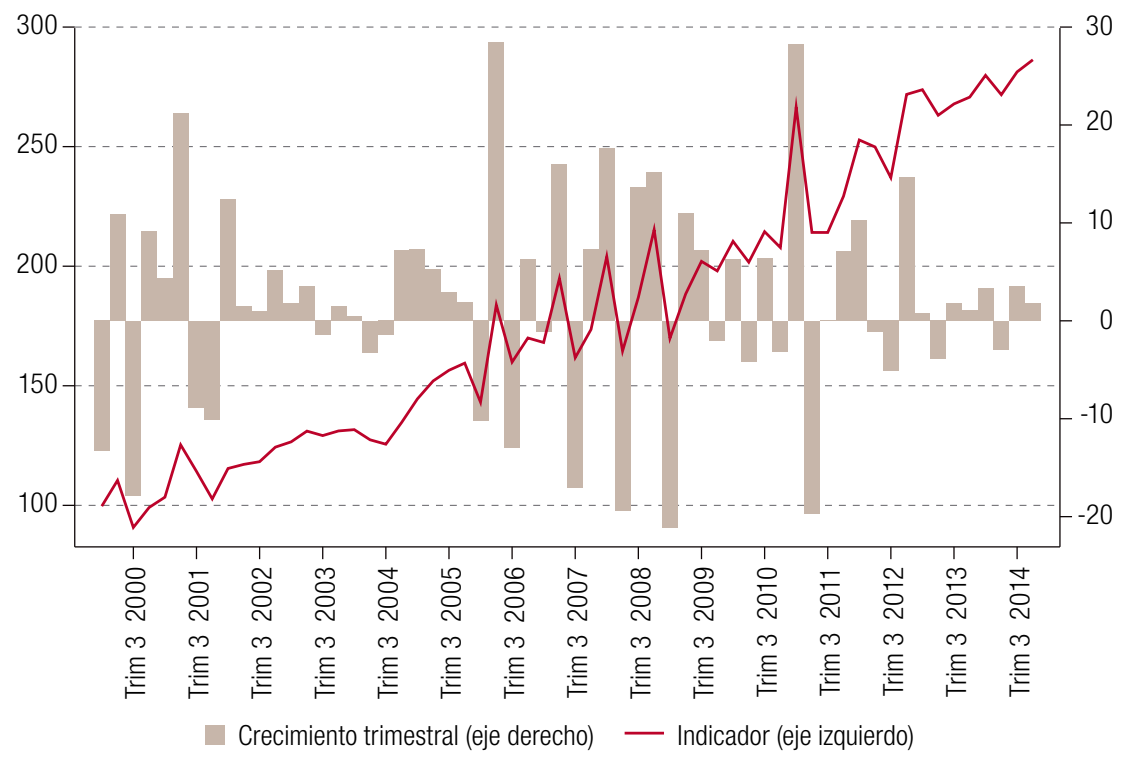

Fuente: Elaboración propia. 